\title{
Marital Status, Partnership and Health Behaviour: Findings from the German Ageing Survey (DEAS)
}

\author{
Regina Hilz, Michael Wagner
}

\begin{abstract}
Numerous empirical studies have confirmed that married people have a lower risk of morbidity and mortality than unmarried people. However, there is relatively little existing research on the impact of marital status and partnerships on the health behaviour of elderly people in Europe. This study examines the association between partnership status and health-related behaviour among the German population in the second half of life (aged 40-85). We focus on four indicators of health behaviour: smoking, physical activity, body weight, and health check-ups. The data used in the analysis come from the $2008(n=6,205)$ and $2014(n=6,002)$ waves of the German Ageing Survey (DEAS). We applied logistic regression models with average marginal effects (AME).

The results of our analysis are in line with the findings of previous studies, which indicated that being married has a protective effect on smoking and a negative effect on body weight. Crisis effects are found to be limited primarily to smoking by recently widowed people. Our study provides new empirical insights into the extent to which being married has protective effects on the use of health care, as people who are separated, divorced, or never married are found to be less likely to have regular health check-ups compared to married people. Furthermore, our results for physical activity are contrary to previous findings for younger adults, according to which being married is associated with a lower likelihood of participating in physical activities. The results of the data analyses show that at ages 40 and older, unmarried individuals, especially those who are not in a partnership, are at higher risk of physical inactivity than their married counterparts. Our findings on marital status and partnership status therefore demonstrate that being married is strongly associated with positive health behaviours. The results may be useful for designing health programmes or prevention measures.
\end{abstract}

Keywords: Marital status · Partnership · Protection effect · Health behaviour · German Ageing Survey 


\section{Introduction}

A very large number of empirical studies have demonstrated that being married is associated with a wide range of health benefits (Hughes/Waite 2009; Joung et al. 1994) and longevity (Hu/Goldman 1990; Klein 1993; Manzoli et al. 2007; Robards et al. 2012). Previous research on the relationship between health and marital status has shown that, on average, divorced and separated people are in the worst health condition, with the highest rates of acute and chronic diseases (Grundy/Tomassini 2010); widowed people are in the second-worst health condition (Grundy/Sloggett 2003; Perkins et al. 2016); and never-married people are in the third-worst health condition (Grundy/Tomassini 2010). It has also been found that the experience of marital dissolution negatively affects health over a long period. Based on data from the Health and Retirement Study (HRS), Hughes and Waite (2009) found evidence of a long-term effect of marital disruption on the health of people aged 50 and older. Their results showed that compared to people in their first marriage, people who are currently married but have ever been divorced have a worse self-rated health, more chronic conditions, more mobility limitations, and more depressive symptoms (Hughes/Waite 2009). They also found that people who are divorced and widowed and do not remarry have worse mental and physical health than people who are currently married (Hughes/Waite 2009). Recent meta-analyses have also indicated that never-married (Roelfs et al. 2011), widowed (Moon et al. 2011), and divorced people (Manzoli et al. 2007; Sbarra/Nietert 2009) have higher mortality risks than married people.

In turn, the evidence that married people have lower morbidity and mortality risks than unmarried people has been attributed to lifestyle factors. However, the relationship between marital status and health behaviour remains unclear. On the one hand, recent research has suggested that being married is associated with engaging in healthier behaviours, such as consuming less nicotine (Cho et al. 2008; Peltonen et al. 2017) and alcohol (Duncan et al. 2006; Reczek et al. 2016). However, studies have consistently shown that being married can have negative effects on body weight (Averett et al. 2008; Klein et al. 2013; Sobal et al. 2003; Umberson et al. 2009) and physical activity (Kaplan et al. 2001; Rapp/Schneider 2013).

Only a few existing studies have examined the influence of partnership or marriage biographies on the health behaviour of elderly people in Europe (e.g., Grundy/ Tomassini 2010). There are, however, a number of studies conducted in the U.S. that have looked at the effects of partner-specific characteristics on the health behaviour of elderly people (Bulanda 2006; Reczek et al. 2016; Wilcox et al. 2003). But as European populations age and demographic and social changes continue, research on the health behaviour of elderly people is becoming increasingly important. Compared to other age groups, older people who are married face a higher risk of losing their partner. Moreover, divorce and separation are becoming increasingly common life events among older people (Nowossadeck/Engstler 2013). Taking into account the point in time when marriage dissolution occurs allows for the analysis of longterm and short-term effects on health behaviour (see generally Chase-Lansdale/ Hetherington 2014), and for the control of selection mechanisms. 
This work broadens the research landscape by focusing on older unmarried cohabiters in Germany. Our analysis considers the effects of being an unmarried cohabiter and the timing of marriage dissolution on different dimensions of health behaviour. In addition to examining the role of marital status in health behaviour, we investigate the partnership status of unmarried people to identify differences in the health behaviour patterns of married people and unmarried cohabiters (Fuller 2010).

We take into account four indicators of health behaviour: smoking, physical activity, body weight, and having regular health check-ups. Smoking, physical inactivity, and high a body weight can be considered health-related risk behaviours because they are associated with increased risks of morbidity and mortality (see Committee on Health and Behavior 2001: 87-137; World Health Organization 2009: 9). Additionally, body weight is a useful indicator of patterns of physical inactivity and unhealthy nutrition (Psouni et al. 2016). The fourth behaviour, having regular health check-ups, is used here as an indicator for engagement in health-related prevention measures. Studying the health behaviour of older adults is important because having a healthy lifestyle in old age is positively related to reduced morbidity and mortality risks (Haveman-Nies et al. 2003). Accordingly, the present study deals with the questions of whether and, if so, how marital status, partnership status, and the timing of marriage dissolution are associated with smoking, physical activity, body weight, and having regular health check-ups in late adulthood.

\section{Theoretical Perspectives on Partnership and Health Behaviour}

Based on the model developed by House, Umberson, and Landis (1988), Figure 1 shows the relationship between marital and non-marital partnership, stress, healthrelated behaviour, and health. Three explanatory approaches have been established to disentangle the relationship between marital status, partnership status and health behaviour: protective effects, selection effects, and crisis effects.

The assumption that a partnership has protective effects on health behaviour is based on the concept of social support, social control, and social regulation (Goldman et al. 1995; Umberson 1992). According to the concept of social support, a partnership is a close social relationship that has a health-promoting effect through different types of supportive behaviour by the partners (Heaney/lsrael 2008: 190; Umberson et al. 2010: 144-145). Emotional support is expressed as empathy, love, trust, care, appreciation, and acceptance. Instrumental support includes the provision of material assistance and services that help a person in need (Heaney/lsrael 2008: 190). A typical example of material assistance is the pooling of money to share the costs of the home. Services for the partner could be e.g. cooking a meal, arranging medical appointments, or taking care of the child(ren). Informational support is provided within couples through the exchange of information that facilitates decision-making. These different types of support may lead to the positive regulation of health-related behaviours among (married) partners (Grundy/Tomassini 2010: 1472; Umberson et al. 2010). For example, the lifestyle of a couple is generally 
Fig: 1: Relationship between partnership, health behaviour, and health

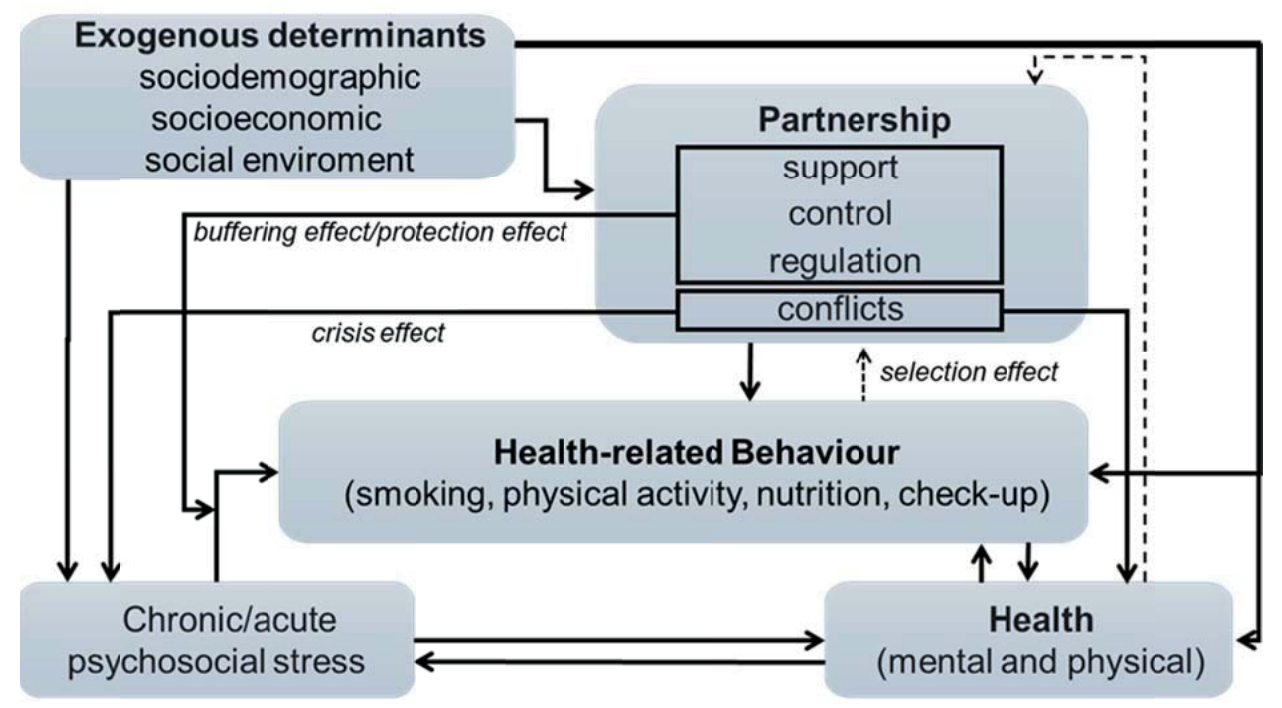

Source: Own design based on House et al. 1988

characterised by having a regulated and communal daily life, including having regulated and organised leisure time; eating healthy and regular meals; and providing and receiving care and assistance in difficult life situations, including illness (Burke et al. 1999; Rapp/Klein 2015). Partners may benefit from the emotional, instrumental, and informational support they receive from each other in stressful situations (Böhr 2015; Cohen 2004). According to the stress-buffering hypothesis (Cohen/Wills 1985), the social support provided within partnerships has positive effects on the physical (Uchino 2004) and the psychological health (Soulsby/Bennett 2015) of the partners. The buffering effect of being married or in a partnership, also shown as an arrow in Figure 1, moderates the effect of stress on health behaviour. Men in particular are more likely to engage in positive health behaviour if they receive social support from a wife or partner (Böhr 2015; Waite/Gallagher 2000).

Health behaviour is also influenced by social control. The protective effect of partnerships is based in part on the tendency of partners to monitor each other, and to sanction adverse health behaviours (Umberson 1992). Thus, the health-related behaviours are regulated through the support and motivation they receive from their partner to engage in a health-conscious lifestyle and to limit their risk-taking behaviours. Partners may have a strong interest in discouraging each other from acting in self-harming ways, both out of a sense of responsibility for the other person and out of self-interest. By encouraging each other to remain healthy, the partners are seeking to avoid financial losses and the restrictions they would experience in caring for a disabled or ill spouse. This tendency to regulate the behaviour of the partner can be called social regulation (Duncan et al. 2006). Accordingly, the protective effect of partnerships involves a complex set of mechanisms that promote 
health behaviour through ecological, social, and psychological factors (see Goldman et al. 1995: 1717; Rapp/Klein 2015: 776; Williams/Umberson 2004).

The protective effect of living in a marital or non-marital partnership can, however, disappear if the partnership quality is low. A relationship marked by conflict can cause the partners to feel stressed (Bulanda et al. 2016; Floyd et al. 2006), suffer from poor health (Choi/Marks 2008), and engage in unhealthy behaviour (Reczek et al. 2016). Furthermore, if a relationship is of low quality, the risk of separation or divorce increases. The conflicts in the relationship and the dissolution of a partnership are thus said to have a crisis effect (see Fig. 1).

The crisis-based approach emphasises that health behaviour may not only be explained by marital or partnership status, but by critical life events, such as marriage dissolution like a separation, divorce, or widowhood (Booth/Amato 1991; Bulanda et al. 2016; Wilcox et al. 2003; Williams/Umberson 2004: 81-82; Wyke/Ford 1992: 524). Contrary to the protection and selection approaches, the crisis model assumes that health and health behaviour are determined by the economic, physical, and psychological burdens associated with marital dissolution (see Booth/Amato 1991; Wyke/ Ford 1992). In addition to having negative economic effects (see Bröckel/Andreß 2015), the stress-triggering circumstances of a marriage dissolution have physiological, psychological, and social consequences (Umberson 1992; Williams/Umberson 2004). Under these negative circumstances, the partners may develop risky health behaviours, such as increased nicotine or alcohol consumption (see Reczek et al. 2016; Tamers et al. 2014). According to the crisis model, a person's marital history, such as the time since separation or widowhood, has important effects on his/her health behaviour (Grundy/Tomassini 2010). The longer the period since the dissolution of the marriage, the more likely it is that the individual will have adapted to the situation, and the less severe will be the effects on his/her health behaviour. It is therefore assumed that patterns of risky health-related behaviour will be observed more frequently among individuals who are recently separated or widowed than among people who have lived without a partner for many years. Thus, when investigating the relationship between health behaviour and marital status, it is important to take into account the short- and long-term effects of marriage dissolution.

In contrast, the selection theory calls into question the protective effect of marriage, and suggests instead that there is a reversed cause-and-effect chain (see Goldman 1993; Waldron et al. 1996). According to the selection approach, healthy people have a higher probability of getting married (Lipowicz 2014; Unger 2007; Waldron et al. 1996) and of staying married (Hughes/Waite 2009), whereas less healthy people either do not marry or are more likely to separate or divorce (Cheung 1998; Joung et al. 1998; Rapp 2012).

Furthermore, a person's health status can influence his/her health-related behaviours (Committee on Health and Behavior 2001). For example, unhealthy people are less likely than healthy people to be physically active. Other influencing factors related to health behaviour, marital status, and stress are characteristics of the external environment and determinants of social inequality, such as socio-demographic characteristics (e.g., age, gender, ethnicity) and socio-economic characteristics (e.g., education, income, occupation) (Hedwig et al. 1999; Schmidtke/Meyer 
2011). Health and health behaviour are also affected by cultural factors and regional conditions, such as housing conditions and access to quality health care (Wilkinson/ Marmot 2003). One important socio-demographic factor is the age of the individual, as a person's biological age can influence his/her health and health behaviour, as well as his/her marital status and stress levels. Being older can negatively affect a person's mental and physical health, as the risk of disease and the risk of death increases with age. The likelihood that stressful events such as the death of one's partner will occur also rises with age. Thus, age-dependent effects should be taken into account when determining health behaviour. In the perspectives we present in the following sections, health behaviour is viewed as the product of protective and crises effects, as well as environmental conditions.

\section{State of Research}

\section{Partnership and Smoking}

A number of empirical studies have focused on the effect of marital status on smoking behaviour among young adults and middle-aged people. The results of these studies clearly show that the prevalence of cigarette smoking varies considerably according to marital status. German cross-sectional studies have confirmed that married people have lower smoking rates than people who are divorced (Helmert et al. 2001; Schulze/Lampert 2006) or have never been married (Schmidtke/Meyer 2011). Data from the 2003 health survey confirmed that compared to people who are divorced or widowed, people who are married are less likely to smoke; and that if they do smoke, they smoke less (Gross/Groß 2008: 260-261).

The effects of social control and social regulation on smoking behaviour within marriages were confirmed by two European studies. One of them found higher rates of smoking cessation among married couples than among unmarried individuals based on longitudinal data from the British Household Panel Survey (BHPS) (Chandola et al. 2004). A cross-sectional study from the Netherlands confirmed that older people as well as married people had a higher likelihood of quitting smoking, both for men and women (van Loon et al. 2005). Schoeppe et al. (2018) investigated with cross-sectional data the frequency of healthy lifestyle factors in 15,001 Australian singles (never married, widowed, divorced), and couples (married and unmarried). The authors identified trends in these healthy lifestyle factors between 2005 and 2014. Compared to singles, couples were significantly more likely to be non-smoker (Schoeppe et al. 2018). Moreover, a longitudinal study of middle-aged adults in the U.S. by Homish and Leonard (2005) showed that an individual's smoking status tends to influence the smoking behaviour of his/her partner, but that the spousal influence is greater on relapse than on cessation. A Finnish prospective study found that getting and staying married over a nine-year follow-up period was associated with smoking cessation among men, but not among women (Broms et al. 2004). A Swedish longitudinal study also revealed that married women have a stronger influence on the smoking behaviour of their husbands than vice versa (Nystedt 2006). 
These findings indicate that in marriages, men are the main beneficiaries of social support, while women are the key providers of social support.

While the focus of most of these studies has been on the marital status of young and middle-aged people, there is comparatively little evidence on the smoking behaviour of older people in non-marital partnerships. One of the few studies that analysed the smoking behaviour in middle and older age is by Margolis and Wright (2016). Using longitudinal data of the Health and Retirement Study, they found evidence of the association between partnership status and smoking changes which greatly depends on the health behaviour changes of the partner. A smoker who is partnered with a smoker is less likely to stop smoking, while a smoker who is partnered with a non-smoker is more likely to stop smoking. Those recently widowed, divorced, or repartnered have similar smoking changes like the consistently unpartnered.

\section{Partnership, Physical Activity, and Body Weight}

Contrary to the assumption that a marital or non-marital partnership has protective effects, cross-sectional studies have found that physical inactivity and body weight levels are higher among married and unmarried couples than among never married, divorced and widowed people (Averett et al. 2008; Klein 2011; Klein et al. 2013;). The reasons why couples tend to weigh more include their tendency to consume more calories by eating more frequent and more regular meals (see Jeffrey/Rick 2002), and to have lower activity levels (Averett et al. 2008). In addition, people tend to consume larger and more generous quantities of food when in company than when alone (Castro 2002). Finally, marriage dissolution is often accompanied by changes in behaviour, which may lead to changes in body weight (Greeno/Wing 1994; Umberson et al. 2009; Williams/Umberson 2004). Having a lower body weight, for example, might improve a single person's chances on the partner market (Averett et al. 2008; Klein 2011). The stress and grief that are typically associated with divorce or widowhood may also lead to weight loss (Umberson et al. 2009).

A number of studies have also confirmed that there is a negative relationship between physical activity and marriage. Using longitudinal data from the German Socio-Economic Panel (GSOEP), Rapp and Schneider (2013) found evidence of reduced levels of physical activity among people in all types of relationships (unmarried cohabiting, married, and dating). ${ }^{1}$ The effects were shown to be strongest for married couples and weakest for dating couples. The analysis further showed that for married men, the negative effects of living together on physical activity became weaker with increasing age; while for women, the negative effects on physical activity decreased and became negative with increasing age. In line with the findings for body weight, leaving the partner market has been shown to have negative effects on physical activity (see Rapp/Schneider 2013). However, an American longitudinal

1 Here, a dating relationship is defined as a partnership with separate households; also called living apart together (LAT) partnership. 
study found that the transition from single life to marriage resulted in a significant positive change in physical activity (King et al. 1998). Based on a retrospective survey of 50-70-year olds in Germany, Klein (2009) found that a partnership favours the dissemination of physical activities, but the beginning of a partnership also increases the exit rate of sport activities. Another cross-sectional study supported these findings for older adults in the U.S., as it found that older couples (aged 70-79) had higher physical activity levels than older unmarried adults (Pettee et al. 2006). These findings may be explained by the effects of social control of and social support for physical activity by partners in old age. As a consequence, unmarried cohabitation or marriage may become a more positive predictor of physical activity in older age.

\section{Partnership and Health Check-ups}

Very few previous studies have examined the extent of a partnership's or marriage's impact on having regular preventive health check-ups. Health check-ups have been available to people aged 35 and older in Germany since 1989. During a health checkup, the physician examines cardiovascular disease risk factors, such as raised cholesterol levels and high blood pressure; as well as signs of diabetes mellitus type 2 and kidney disease. According to Verbrugge (1979: 269), married people rarely use health services because their day-to-day lives and leisure time are constrained by the responsibilities of family life and by the pressure to meet role-specific expectations. Verbrugge (1979: 269) therefore concluded that unmarried people have more flexibility and leisure time to use health care services. Recent cross-sectional studies, however, show just the opposite. Being married is a positive factor for visits to specialist doctors (Yom Din et al. 2014) and for increased utilisation of cancer screening (Hanske et al. 2016). The influence of marital status was greater among men relative to woman eligible for cancer screening (Hanske et al. 2016).

However, according to the hypothesis of social support and social control, the motivation and the pressure to take advantage of health care services should be more prevalent among couples. Hence, a married/partnered person may encourage his/her partner to have the recommended health screenings in order to avoid the multiple burdens that would arise if the partner had a disease that was diagnosed or treated too late. Accordingly, married/partnered people should be more likely to participate in health screenings than people without a partner. In addition, people in partnerships tend be in a better financial position than single people, and can thus more easily afford to spend money on health services. If a person is ill, consulting with his/her partner could be a coping strategy as well. Results from the HEALSEE project "Healthcare-seeking by older people in Germany" (2012-2015) showed that when respondents feel sick, they usually first seek advice from their partner, regardless of the level of medical competence they attribute to the partner (Böhr 2015). A cross-sectional study based on the 2010 Korean National Health and Nutrition Examination Survey showed that the health screening rate was higher among men living with a partner than among men without a partner (Yim et al. 2012). In women, no significant relationship was found between the likelihood of undergoing health screenings and marital status (Yim et al. 2012). Findings from Prigerson et al. (1999) 
indicated that widowhood was associated with worsened health, but not with greater health service use. Separated women and women divorced from a discordant marriage were not more depressed but made more excessive use of mental health services. According to these results marital harmony appears protective against doctor visits.

In light of the current findings, there is sparse evidence of the relationship between partnership status and health check-ups among older people. Furthermore, little is known about the impact of marital dissolution on the likelihood of using health care services.

\section{Hypotheses}

Based on the conceptual framework of House, Umberson, and Landis (1988), we investigate the extent to which being in a married or an unmarried partnership has a protective or buffering effect among older adults on the probability of smoking, being physically inactive, being overweight, and avoiding regular health check-ups. In addition, we seek to shed light on the crisis effects of health behaviour by considering the short- and the long-term effects of divorce, separation, and widowhood.

Our first hypothesis suggests that compared to their married counterparts, elderly people who are not married have significantly higher probabilities of smoking, being physical inactive, being overweight, and avoiding regular health check-ups. These assumptions are based on the expectation that married people are more likely than unmarried people to be influenced by high-quality social support, regulation, and control. A marriage represents an institutionalised relationship between a man and a woman that is associated with certain rights and duties that "simple" partnerships lack. Accordingly, a married person's influence on and interest in his/ her partner's behaviour are likely to be greater than an unmarried person's:

Hypothesis 1: Being married has protective health effects, whereas unmarried people with and without a partner are significantly more likely than married people to engage in unhealthy behaviours including smoking, being physical inactive, being overweight, and avoiding regular health check-ups.

The second hypothesis predicts that there are significant differences in the health behaviour patterns of unmarried people depending on their partnership status. There is, for example, a buffering effect when entering a new partnership after a marital dissolution, which reduces the negative consequences of the stressful life event. In addition, unmarried partners (who have not been married before and thus have not experience divorce or the like) are likely to experience forms of social support and control through the partnership that contribute to a health-conscious lifestyle:

Hypothesis 2: People who are not in a partnership experience no protective effects on their health behaviour. Consequently, people who are not in a partnership are at higher risk of engaging in unhealthy behaviour (including smoking, being physical inactive, being overweight, and avoiding regular health check-ups) than people who are in a partnership. 
The third hypothesis assumes that adjustment processes occur over time. According to the crisis concept, people who have recently been divorced, separated, or widowed should be more likely to smoke, have higher levels of physical inactivity, be overweight, and avoid regular health check-ups than their counterparts who were divorced, separated, or widowed long ago:

Hypothesis 3: Marital dissolution is a stressful life event that has a negative impact on health behaviour. Thus, people who have recently been divorced, separated, or widowed are more likely to engage in unhealthy behaviours (including smoking, being physical inactive, being overweight, and avoiding regular health check-ups) than people who have been separated or widowed for a long period of time.

\section{Data and Methods}

This study uses data from the German Ageing Survey (Deutscher Alterssurvey; DEAS). The DEAS is a nationwide representative cross-sectional and longitudinal survey of the German population aged 40 and older. The first DEAS survey took place in 1996, and further waves were conducted in 2002, 2008, 2011, and 2014. The surveys in 2002, 2008, and 2014 considered a cross-sectional sample as well as a panel sample of study participants who had entered the DEAS earlier (Klaus/Engstler 2016). In 2011, only respondents who had participated in the previous waves were interviewed. A computer-assisted personal interview (CAPI) was used as the main data selection instrument, and was implemented by means of a standardised questionnaire. After participating in a personal interview, respondents received an additional paper-and-pencil "drop-off" questionnaire that they were expected to fill out on their own.

The questions about health behaviours were asked in different waves but only sport activities were collected in all waves. Body mass index (BMI) and smoking was part of 2002, 2008, 2011, and 2014. The health check-up variable $(2008,2011,2014)$ is only available for a period of six years. Therefore, all health behaviours are part of the 2008, 2011, and 2014 waves. In addition to the health behaviour variables, we are interested in information on marital status and non-marital partnerships. Marital status and partnership status have been recorded since 1996 by the main interview. Due to the repeated questioning of the persons over a long time period, the DEAS would qualify for a longitudinal analysis. In order to examine the impact of marital status on health behaviour, it is important to compare the health behaviour during marriage (t1) and after marriage (t2). In wave 2008, 2011 and 2014 all variables that indicate different types of health behaviour are included. Thus, we have to search for persons who were married in 2008 or 2011 and experienced a separation, divorce or widowhood between 2008 and 2014. Table A1 in the appendix gives an overview of the number of persons who experienced a marriage dissolution during the DEAS waves 2008, 2011, and 2014. Only 44 people experienced a change from married to separated or divorced and 94 persons were widowed. In addition, not all of these persons provided information on the dependent variables. Only 27 of the 44 separated/divorced persons and only 60 of the 94 widowed provided information 
about their smoking behaviour and health check-ups. Furthermore, in the longitudinal data only a few intrapersonal changes in the health behaviour variables can be observed, if a small amount of time and few cases are available (see Table A1 in the appendix). For a test of the second hypothesis, partnerships of unmarried persons are relevant. However, the number of people in non-marital partnerships that experienced a separation is extremely low in the longitudinal data set $(n=101)$. A small sample size has a higher risk of biased fixed effect estimates. For this reason, we decided to perform a cross-sectional analysis to compare the health behaviour of married and unmarried people and of people according to their partnership status.

The data used in the present study stems from the baseline samples of 2008 and 2014. The pooled dataset comprises in total 12,207 individuals aged 40 to 85 , of whom 6,205 came from the base sampling of 2008, and 6,002 came from the base sampling of 2014 (see Table 1). ${ }^{2}$

Our final sample consists of individuals who were living in a private household and were born between 1923 and 1974. The survey response rate was 39 percent for the sample in 2008 and 27 percent for the sample in 2014 (Infas 2009: 49-54; Engstler/Hameister 2016: 9).

The major strength of our dataset is that it contains a large amount of information on partnership status and health behaviours, which are described in more detail in the following section. Table 1 shows the unit and mean values of the examination variables, as well as the numbers of missing values.

\section{Health behavioural indicators}

The dependent variables are four different indicators of health behaviour: smoking status, physical activity, BMI, and having regular health check-ups. The data on smoking and having regular health check-ups were collected via the drop-off questionnaire. The information on physical activity, self-reported body size and body weight for calculating the BMI were collected within the main interview (CAPI).

In line with criteria of the World Health Organization, thresholds were defined for the health behavioural indicators associated with increased risks of morbidity and mortality (World Health Organization 2009). We assigned the value of one for a behaviour that is defined as harmful to health, and we otherwise assigned the value of zero.

Smoking of cigarettes is defined as harmful to health because it has been linked to increased risks of certain diseases, such as cardiovascular disease, chronic respiratory disease, cancer, and type 2 diabetes (Mathers 2012: 9). The survey participants were asked: "Do you currently smoke - even if it's only occasionally?" The possible answers were: (1) "Yes, daily", (2) "Yes, occasionally", (3) "No, not anymore", and (4) "I have never smoked". Current smokers were assigned the value of one, while non-smokers and ex-smokers were assigned the value of zero.

2 The analysis refers to the following datasets: SUF DEAS 2008, Version 3.0, DOI: 10.5156/ DEAS.2008.M.003; SUF DEAS 2014, version 1.0, DOI: 10.5156/DEAS.2014.M.001. 
Tab. 1: Characteristics of study participants from the German Ageing Survey (DEAS)

\begin{tabular}{|c|c|c|c|c|}
\hline & \multicolumn{2}{|c|}{2008} & \multicolumn{2}{|c|}{2014} \\
\hline & $\mathrm{N}$ & $(\%)$ & $\mathrm{N}$ & $(\%)$ \\
\hline Total & 6,205 & $(100)$ & 6,002 & $(100)$ \\
\hline \multicolumn{5}{|l|}{ Health behaviour indicators } \\
\hline \multicolumn{5}{|l|}{ Smoking status } \\
\hline Never-Smoker & 2,182 & $(50.1)$ & 1,888 & $(44.4)$ \\
\hline Ex-Smoker & 1,352 & $(31.1)$ & 1,487 & $(34.8)$ \\
\hline Smoker & 816 & $(18.8)$ & 884 & $(20.8)$ \\
\hline Missing values & 92 & & 112 & \\
\hline no drop-off & 1,763 & & 1,640 & \\
\hline \multicolumn{5}{|l|}{ Physical activity } \\
\hline Several times a week & 1,694 & $(27.3)$ & 2,010 & $(33.5)$ \\
\hline Once a week & 1,027 & $(16.6)$ & 1,026 & (17.1) \\
\hline 1 to 3 times a month & 444 & $(7.2)$ & 450 & (7.5) \\
\hline Rarely or never & 3,037 & $(48.9)$ & 2,512 & (41.9) \\
\hline Missing values & 3 & & 4 & \\
\hline \multicolumn{5}{|l|}{ Classification of body weight } \\
\hline Underweight (BMI < 18.5) & 46 & $(0.8)$ & 53 & (0.9) \\
\hline Normal weight (BMI 18.5-24.9) & 2,288 & $(37.9)$ & 2,210 & $(37.8)$ \\
\hline Overweight (BMI 25.0-29.9) & 2,611 & $(43.3)$ & 2,394 & $(40.9)$ \\
\hline Obese (BMI $\geq 30.0$ ) & 1,089 & $(18.0)$ & 1,199 & $(20.5)$ \\
\hline Missing values & 171 & & 146 & \\
\hline \multicolumn{5}{|l|}{ Having regular health check-ups } \\
\hline Yes & 2,987 & $(68.2)$ & 2,650 & $(63.7)$ \\
\hline No & 1,393 & $(31.8)$ & 1,508 & $(36.3)$ \\
\hline Missing values & 62 & & 204 & \\
\hline no drop-off & 1,763 & & 1,640 & \\
\hline \multicolumn{5}{|l|}{ Partnership-specific variables } \\
\hline \multicolumn{5}{|l|}{ Marital status and partnership } \\
\hline Married & 4,290 & $(69.4)$ & 4,086 & $(68.2)$ \\
\hline \multicolumn{5}{|l|}{ Separated or divorced } \\
\hline Without new partner & 388 & $(6.3)$ & 454 & (7.6) \\
\hline With new partner & 134 & $(2.2)$ & 180 & (3.0) \\
\hline \multicolumn{5}{|l|}{ Widowed } \\
\hline Without new partner & 634 & $(10.3)$ & 483 & (8.1) \\
\hline With new partner & 60 & $(1.0)$ & 70 & (1.2) \\
\hline
\end{tabular}


Tab. 1: Continuation

\begin{tabular}{|c|c|c|c|c|}
\hline & & & & \\
\hline & $\mathrm{N}$ & $(\%)$ & $\mathrm{N}$ & $(\%)$ \\
\hline Never married & & & & \\
\hline Without partner & 326 & (5.3) & 320 & (5.3) \\
\hline With partner & 352 & (5.7) & 403 & (6.7) \\
\hline Missing values & 31 & & 7 & \\
\hline Time since divorce or sep & & & & \\
\hline Longer than 5 years & 471 & $(72.4)$ & 593 & $(76.6)$ \\
\hline Less or exactly 5 years & 180 & $(27.6)$ & 181 & $(23.4)$ \\
\hline Missing values & 23 & & 18 & \\
\hline Duration of widowhood & & & & \\
\hline Longer than 5 years & 478 & $(65.3)$ & 397 & $(66.5)$ \\
\hline Less or exactly 5 years & 254 & (34.7) & 200 & $(33.5)$ \\
\hline Missing values & 9 & & 8 & \\
\hline Covariates & & & & \\
\hline Gender & & & & \\
\hline Female & 3,072 & $(49.5)$ & 2,937 & $(48.9)$ \\
\hline Male & 3,133 & $(50.5)$ & 3,065 & (51.1) \\
\hline Age (in years) & & & & \\
\hline 40 to under 55 years & 2,072 & $(33.4)$ & 1,788 & $(29.8)$ \\
\hline 55 to under 70 years & 2,151 & $(34.7)$ & 2,247 & $(37.4)$ \\
\hline 70 to 85 years & 1,982 & (31.9) & 1,967 & $(32.8)$ \\
\hline Level of education (ISCED & & & & \\
\hline Low & 716 & $(11.5)$ & 497 & (8.3) \\
\hline Medium & 3,374 & $(54.4)$ & 3,138 & $(52.3)$ \\
\hline High & 2,112 & $(34.1)$ & 2,366 & $(39.4)$ \\
\hline Missing values & 3 & & 4 & \\
\hline Self-rated health (SRH) & & & & \\
\hline good & 3,368 & $(54.4)$ & 3,197 & $(53.3)$ \\
\hline fair & 2,079 & (33.5) & 2,081 & $(34.7)$ \\
\hline poor & 748 & $(12.1)$ & 716 & $(12.0)$ \\
\hline Missing values & 10 & & 8 & \\
\hline
\end{tabular}

Source: German Ageing Survey base sample from 2008 and 2014, own calculation, unweighted.

Physical activity was measured by asking: "How often do you do sports such as hiking, soccer, gymnastics, or swimming?" The possible answers were: "daily" (1), "several times a week" (2), "once a week" (3), "1-3 times a month" (4), "less often" (5), and "never" (6). Participants who gave the "less often" and "never" responses were assigned the value of one. 
The BMI was calculated as weight in kilogrammes, divided by height in square metres $\left(\mathrm{kg} / \mathrm{m}^{2}\right){ }^{3} \mathrm{BMI}$ values were classified into four groups: underweight $(\mathrm{BMI}<18.5)$, normal weight (BMI 18.5-24.9), overweight (BMI $\geq 25$ ), and obese (BMI $\geq 30.0$ ) (see World Health Organization 2000: 9). BMI values of 30 and over were defined as risky to health because of the increased risk of disease with the presence of obesity (World Health Organization 2000: 6-11) and were thus assigned the value of one.

Regarding health check-ups, participants were asked: "Doctors often recommend vaccinations and various types of health screening. In the past years, did you regularly have a health check-up?" The value of one was assigned to those who did not have regular health check-ups.

\section{Partnership-specific variables}

The variable partnership status contains information on the partnership-based living arrangements (Engst/er/Hameister 2016: 35). We distinguish between people who are living in a household without a partner (singles) and those living with a partner Partnerships with separate households (living apart together; or LAT) are not taken into account because of the relatively small number of older couples who do not share a household (about 4 percent). The marital or partnership status is operationalised as follows: married (1), separated, or divorced with a new partner (2) and without a partner (3); widowed with a partner (4) and without a partner (5); and never married with a partner (6) and without a partner (7). These categories were recoded as dummy variables. Married people serve as the reference category. Due to the relatively low number of separated people in our sample $(n=206)$, this group was merged with divorced people $(n=1,218)$.

To capture short- and long-term effects on health behaviour, the time since marriage dissolution is considered using four categories: people who have been widowed for at least five years (1) or less than five years (2); people who have been divorced or separated (3) for five or more years; and people who have been separated or divorced for less than five years (4). Married people again served as the reference category.

\section{Covariates $^{4}$}

We consider a number of control variables that are likely to be related to health behaviour and partnership status (Hedwig et al. 1999; Schmidtke/Meyer 2011). Gender and age are related to smoking, utilisation of health care services, physical activity, and body weight. Studies have confirmed that marriage is more beneficial for men

3 It should be noted that studies have established that the level of the self-reported weight is often inaccurate. Thus, relying on self-reported weight can lead to an underestimation of the prevalence of overweight (Dauphinot et al. 2009).

4 We tested the covariates for multicollinearity using the Variance Inflation Factor (VIF) method. Multicollinearity was not detected (VIF values $<10$ ). 
than for women (e.g., Umberson 1992). It has been shown that men in particular are less likely to engage in risky health behaviour through the social support of their wife. There is, for example, evidence that, on average, a wife has a greater influence on her husband's smoking behaviour (by, for example, promoting smoking cessation) than vice versa (Nystedt 2006). Age is also a relevant factor in the relationship between health behaviour and marital status. With increasing age, the probability of being married, divorced, or widowed rises. Health-conscious behaviour is observed more frequently among older than younger people. To measure respondents' socioeconomic status, the International Standard Classification of Education (ISCED) is applied. The following three groups are considered: low educational level (ISCED 0, 1, and 2), medium educational level (ISCED 3 and 4), and high educational level (ISCED 5 and 6) (OECD 1999). It is likely that a higher socioeconomic status is related to a more positive health-related behaviour. Less educated persons may have a lack of knowledge and access to information about health risks. In addition, people in disadvantaged social positions experience more stress through negative life events such as unemployment and financial loss. Under these circumstances, smoking, overeating, and inactivity help to cope with negative emotions among the disadvantaged (Pampel et al. 2010). As health status is strongly associated with health-related behaviour (Committee on Health and Behavior 2001), we control for self-rated health (SRH) as well.

\section{Methods}

Logistic regression is applied to test whether participation in the drop-off questionnaire depended on gender, age, health status, marital status, and region. A significantly lower probability of participation in the drop-off questionnaire is found among divorced and unmarried people than among married couples. The probability of participating in the drop-off questionnaire increases with age, and is much higher among those with poor than with good self-rated health. Thus, elderly, married, and sick people were more likely than other people to have answered the questions about smoking and health check-ups in the written questionnaire. Given the selection effects in data collection based on the survey method, we control for age, gender, and health in the analyses.

Following Allison (1999) and Mood (2010), we conduct logistic regression models with average marginal effects (AME). Average marginal effects indicate "by how many percentage points the probability of the event of interest changes on average across all (group-specific) observations if the explanatory variable increases by one unit" (Auspurg/Hinz 2011: 66; translation by the author). Thus, we compare the health behaviour between different partnership types and investigate the question, whether the influence of being in a partnership is greater than the influence of being partnerless on risky health behaviours. The underlying equation of marginal effects (AME) for dummy variables (xj) reads as follows (Auspurg/Hinz 2011: 66):

$$
\mathrm{AME}_{\mathrm{j}}=\frac{1}{\mathrm{n}} \sum_{\mathrm{i}=1}^{\mathrm{n}}\left\{\left(\mathrm{F}\left(\mathrm{Z}_{\mathrm{i}} \mid \mathrm{x}_{\mathrm{ij}}=1\right)-\mathrm{F}\left(\left(\mathrm{Z}_{\mathrm{i}} \mid \mathrm{x}_{\mathrm{ij}}=0\right)\right\}\right.\right.
$$


The summed distribution function for all observations is marked with the character $F$. The linear predictor is noted for the observation $i$ by $Z_{i}$. AME express the average effect of $x_{\mathrm{ij}}$ on $\mathrm{P}(\mathrm{y}=1)$ by taking the logistic probability distribution function at each observation's estimated logit, multiplying this function by the coefficient for $\mathrm{x}_{\mathrm{ij}}$, and averaging this product over all observations (Mood 2010: 75). The assessment of the influence on health behaviour is carried out separately for the different types of partnerships. From these estimates, the squared difference of the average marginal effects (AME) is calculated to sum the variances of the marginal effects. The calculated result is compared with the critical value for the respective significance level via the $\chi^{2}$ distributions with a degree of freedom.

The extent of partnership-specific differences in smoking behaviour, physical activity, body weight, and the use of health check-ups are subsequently tested by applying logistic regression. ${ }^{5}$ To identify the influence of partnership-specific variables on health behaviour, we have calculated three different regression models for each dependent variable. The first model shows the influence of marital status on health behaviour under the control of covariates. In model 2, the category of never married is further differentiated according to the respective partnership status. The time since marriage dissolution is considered in model 3.

\section{$6 \quad$ Results}

Table 2 shows the results of the logistic regression on the probability of being a smoker and of being physically inactive. Model 1a reveals that separated, widowed, and never-married people have a significantly higher risk of smoking than married people. Separate analyses (not shown) reveal that the widowhood effect depends on the inclusion of the age variable. Widowed people under age 70 are much more likely to smoke than widowed people over age 70 . If age is not controlled for, the low proportion of smokers in the age group 70 to 85 dominates the overall effect. If age is controlled for, the high proportion of smokers among the widowed between ages 40 and 69 dominates the widowhood effect. The results of model 1a are in line with hypothesis 1 , which states that married people are less likely to smoke than unmarried people.

Model 2a shows that separated (or divorced) people without a partner have a 17 percent higher probability of smoking than married people. Separated people with a partner also have a significantly higher probability of smoking (10.6 percent, model 2a) than married people.

Widowed people without a partner are more likely to smoke than those with a partner (model 2a). Compared to married people, never-married people with a partner have an 8.6 percent higher probability of smoking, while never-married people without a partner have a 5.8 percent higher probability of smoking.

5 We use the listwise deletion as a procedure for dealing with missing values, according to which only individuals with valid values are integrated into the analysis (Graham et al. 2003). 
Marital Status, Partnership and Health Behaviour 81

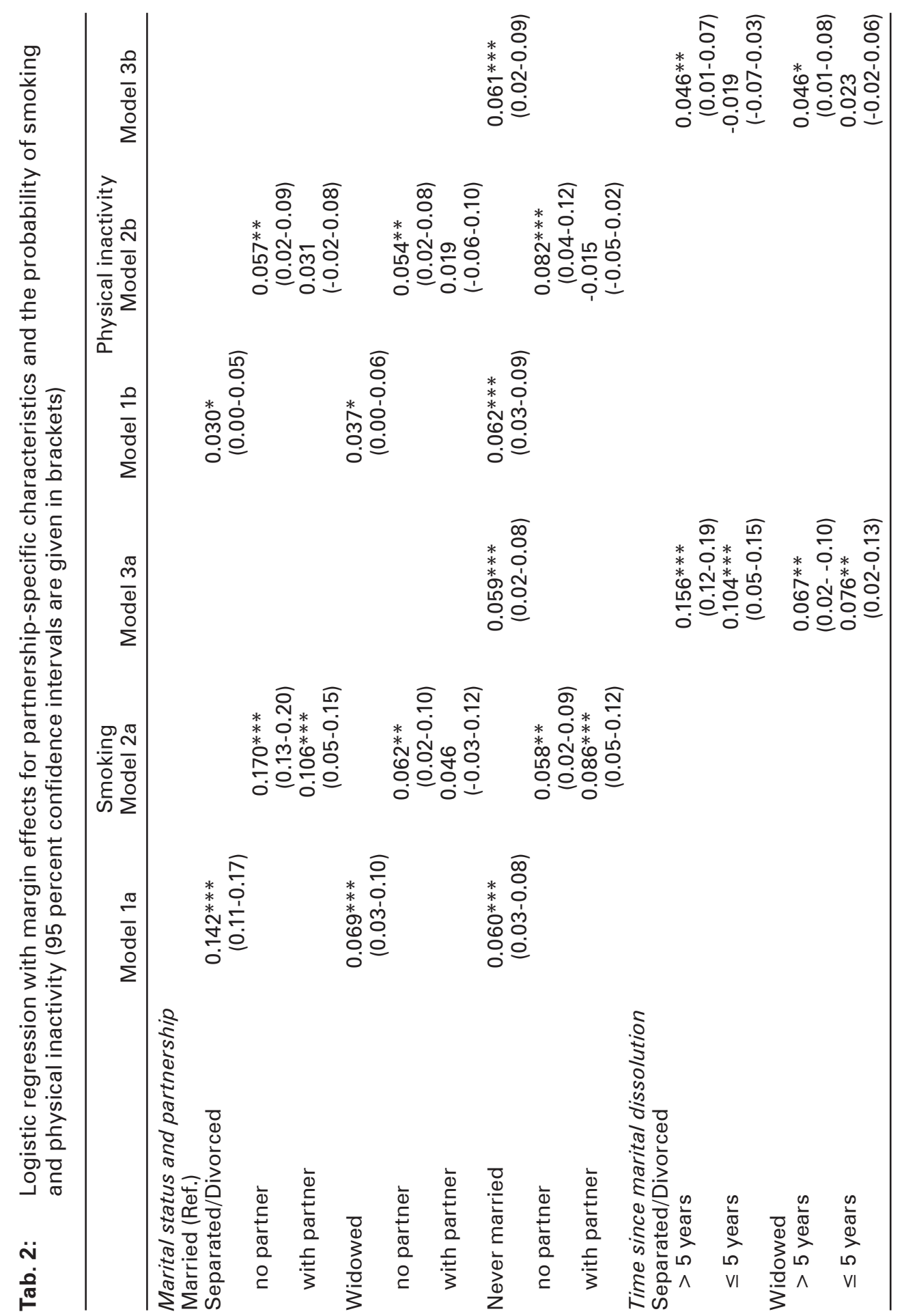




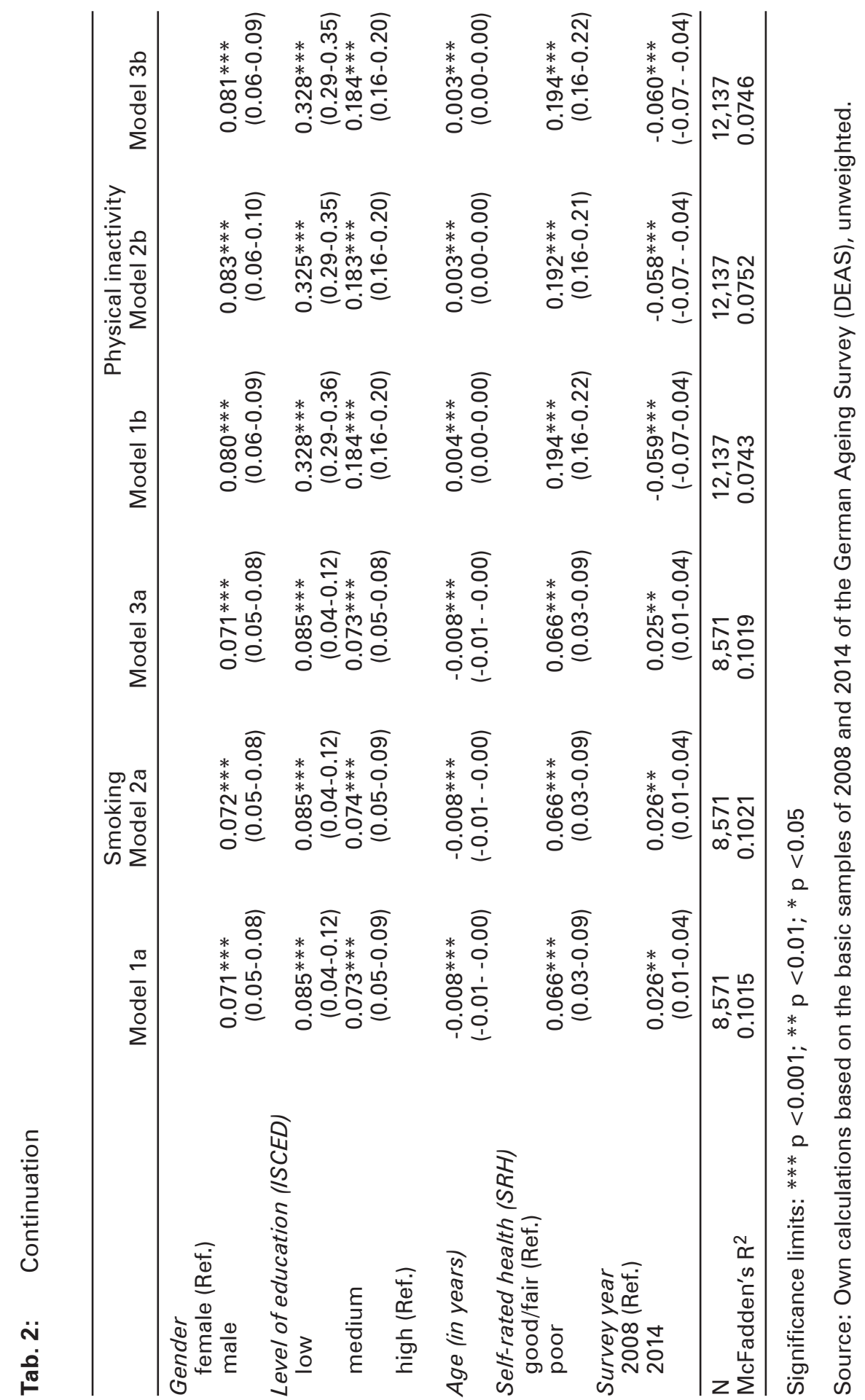




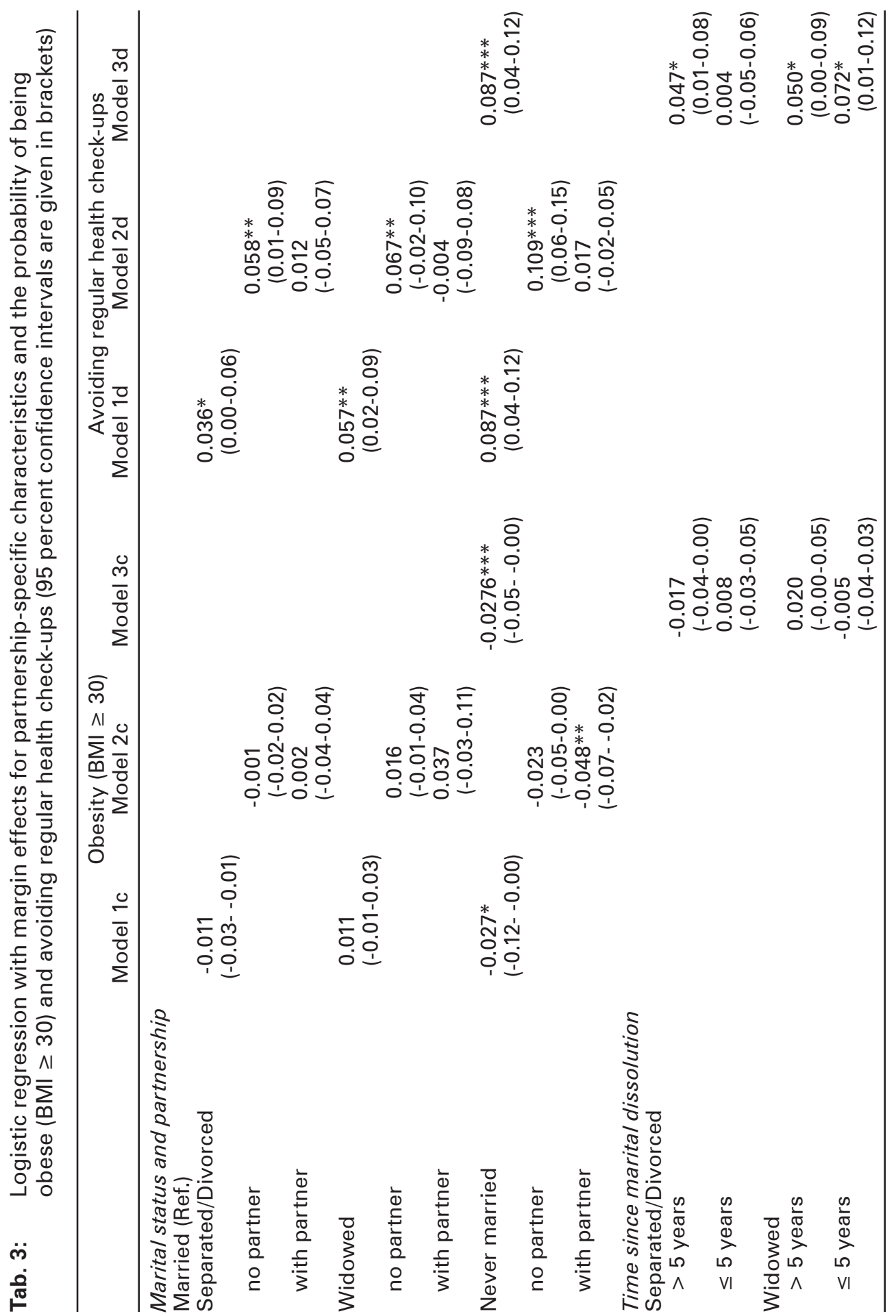


In model 3a (Table 2), we consider the time since marriage dissolution to test hypothesis 3, according to which recently separated and widowed persons have a higher probability of risky health behaviour than people who have been separated or widowed for a long period of time. The results show that both types, people who have been recently or longer separated or widowed, are significantly more likely to be smokers than married people. Thus, the results from model 3a do not suggest that marriage dissolution has a crisis effect. We further observe a decreasing probability of being a smoker with increasing age. Men are more likely to smoke than women. Finally, less educated people are more likely to smoke than highly educated people, and people in poor health are more likely to smoke than people in good health.

Models $1 \mathrm{~b}$ to $3 \mathrm{~b}$ (Table 2 ) summarise the results for physical inactivity. A significantly higher probability of being physically inactive is found for separated (3.0 percent), widowed (3.7 percent), and never-married (6.2 percent) people than for married people. These results confirm our first hypotheses, which state that married couples tend to have healthier lifestyles. We also find that separated, widowed, and never-married people without a partner have a significantly higher risk of being physically inactive than married people. Looking at the time since marriage dissolution, we observe that people who have been separated or widowed for a longer period of time have a higher risk of physical inactivity than married couples. For recently separated and widowed individuals, we found no significant associations for physical inactivity. Again, it is important to keep in mind that time since marriage dissolution and age are correlated. In particular, gender, age, education, self-rated health, and survey year are shown to have high levels of explanatory power for physical activity levels among older people. In contrast to the results of smoking, age increases the risk of being physically inactive. Regarding the survey year, we note a lower probability of physical inactivity in 2014 than in 2008.

Table 3 first shows the results for the outcome "obesity" (BMI $\geq 30$ ). It can be observed that never-married people (-2.7 percent) have a significantly lower probability of being obese than married people (model 1c). For separated and widowed people, no significant margin effects are found. For never-married people with and without a partner, model $2 \mathrm{c}$ indicates a significantly lower likelihood of being obese after controlling for covariates. In this case, only never-married people are found to be less likely to suffer from obesity than married people. In line with hypothesis 1 , these results confirm that marriage has no protective effect on obesity. The results for marital status are in line with those of other studies that postulated a connection between marriage and body weight gain (Averett et al. 2008; Klein 2011; Klein et al. 2013; Sobal et al. 2003). Furthermore, there is a significantly higher risk of obesity in males compared to females, in lower educated people compared to higher educated people, in poor health compared to good health, and the 2014 survey year compared to 2018.

Evidence for a protective effect of marriage is, however, found in the analysis of having regular health check-ups (Table 3). The results of the logistic regression showed for model $1 \mathrm{~d}$ that the probability of avoiding regular health check-ups was significantly higher for separated (3.6 percent), widowed (5.7 percent), and never- 
married people (8.7 percent) without a partner than for married people. Accordingly, hypothesis 1 on the marriage and partnership protective effect can also be confirmed in case of the indicator of having regular health check-ups. Compared to married people, significantly higher marginal effects are identified for recently widowed and people who had been separated and widowed for more than five years (model 3d). Given these results, the presence of a crisis effect on the likelihood of having regular health check-ups can be demonstrated for recently widowed people only. In addition, a higher probability of avoiding regular health check-ups could be confirmed for lower educated people compared to higher educated people and for the survey year 2014 compared to 2008. With age, the probability of not taking part in check-ups decreases.

In Tables 2 and 3, married people are chosen as the reference category to test the protective effect of marriage on health behaviour (hypothesis 1). The results of models $1 \mathrm{a}, 1 \mathrm{~b}$, and $1 \mathrm{~d}$ are in line with hypothesis 1 , according to which unmarried have higher probabilities of smoking, physical inactivity, and avoiding regular health check-ups than married people.

Hypothesis 2 assumes that unmarried people without a partner are significantly more likely to engage in unhealthy behaviour than unmarried people with a partner. Thus, hypothesis 2 suggests that being in a(n unmarried) partnership can have a protective effect on health behaviour. In order to test this hypothesis, a logistic regression was calculated that compared the probabilities of smoking, physical inactivity, obesity, and having regular health check-ups in individuals who are and are not in a (non-marital) partnership. The corresponding results are shown in Table 4. In the first model, we can see the results for people who are and who are not in a (non-marital) partnership. In model 2, the marital status was taken into account. Control variables were included in all models (gender, education, age, self-rated health, and survey year). Compared to unmarried people, a significantly higher probability of being a smoker could only be confirmed for separated people without a partner (see model 2). For physical inactivity and having regular health check-ups, we could confirm hypothesis 2 . Thus, the results show that people in non-marital partnerships are at lower risk of physical inactivity and of avoiding regular checkups than unmarried people without a partner.

Hypothesis 3 focused on the crisis effect of marriage dissolution on health behaviour. According to hypothesis 3 , people who have recently been divorced, separated, or widowed have a higher probability of engaging in unhealthy behaviour than people who lost their partner a long time ago. The results for hypothesis 3 are displayed in Table 5. Contrary to our assumptions, we find that people who have been separated or widowed for a short period of time ( $\leq 5$ years) have higher levels of physical activity. For smoking, obesity, and having health check-ups, the results are not significant. Thus, hypothesis 3 could not be confirmed with the data available. 


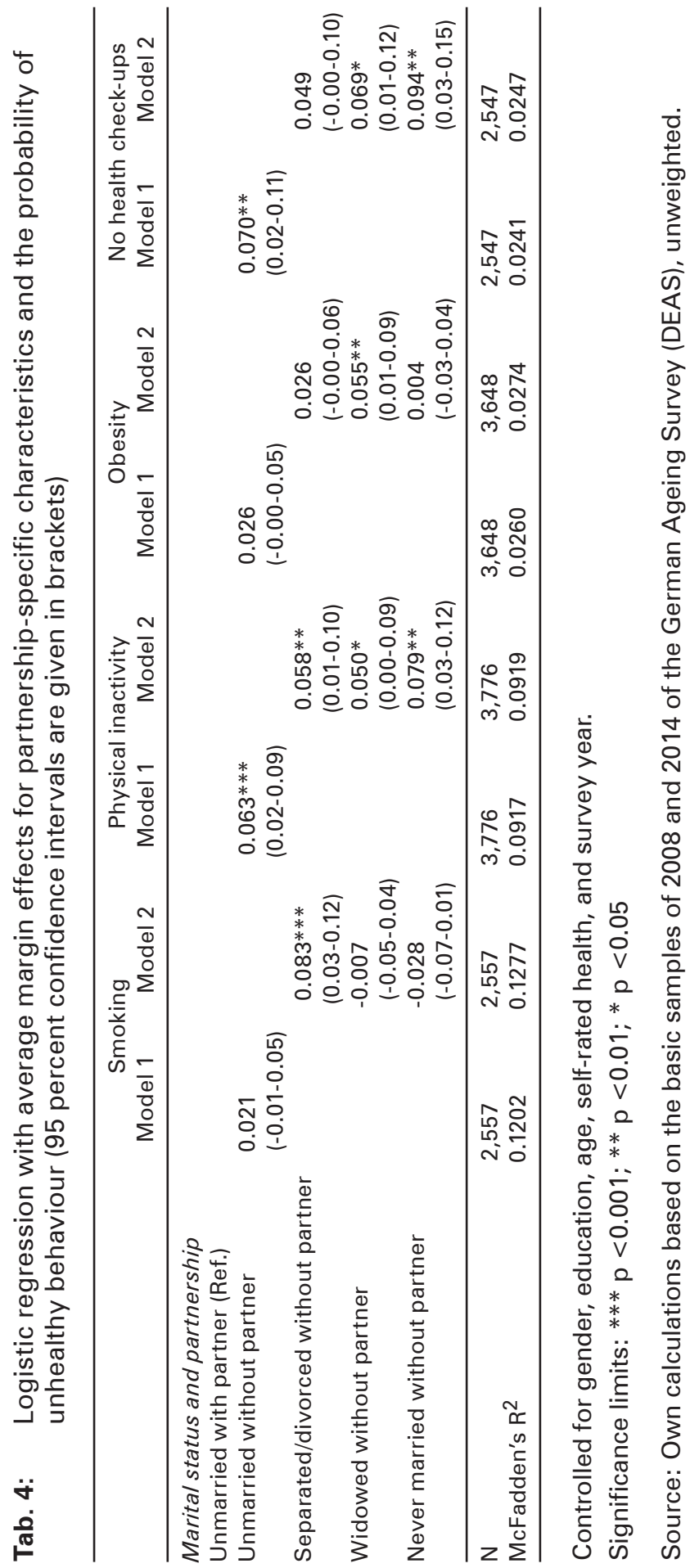


Tab. 5: Logistic regression with average margin effects for the time since marital dissolution and the probability of unhealthy behaviour (95 percent confidence intervals are given in brackets)

\begin{tabular}{|c|c|c|c|c|}
\hline & Smoking & $\begin{array}{l}\text { Physical } \\
\text { inactivity }\end{array}$ & Obesity & $\begin{array}{l}\text { No health } \\
\text { check-ups }\end{array}$ \\
\hline \multicolumn{5}{|l|}{$\begin{array}{l}\text { Time since marital dissolution } \\
\text { Long term ( }>5 \text { years) separated, } \\
\text { divorced, widowed (Ref.) }\end{array}$} \\
\hline $\begin{array}{l}\text { Short term ( } \leq 5 \text { years) separated, } \\
\text { divorced, widowed }\end{array}$ & $\begin{array}{r}-0.037 \\
(-0.07-0.00) \\
\end{array}$ & $\begin{array}{r}-0.040^{*} \\
(-0.07-0.00) \\
\end{array}$ & $\begin{array}{r}-0.000 \\
(-0.03-0.03) \\
\end{array}$ & $\begin{array}{r}-0.002 \\
(-0.05-0.04) \\
\end{array}$ \\
\hline $\mathrm{N}$ & 1,858 & 2,735 & 2,645 & 1,858 \\
\hline McFadden's $\mathrm{R}^{2}$ & 0.1363 & 0.0975 & 0.0225 & 0.0161 \\
\hline
\end{tabular}

Controlled for gender, education, age, self-rated health, and survey year.

Significance limits: ${ }^{* *} \mathrm{p}<0.001 ;{ }^{* *} \mathrm{p}<0.01 ;{ }^{*} \mathrm{p}<0.05$

Source: Own calculations based on the basic samples of 2008 and 2014 of the German Ageing Survey (DEAS), unweighted.

\section{Conclusions}

The focus of this study was to investigate whether being in a married or unmarried partnership and having experienced marriage dissolution are associated with health behaviours of elderly people. Some scientists have identified a causal link between marital status and health in the form of a protective or a crisis effect (Goldman et al. 1995: 1717; Williams/Umberson 2004). However, other scientists have found no evidence of such a causal relationship, and have instead highlighted selection effects for marital status-specific differences in health behaviour (Joung et al. 1998; Waldron et al. 1996).

Against this background, we examined the extent to which marriage has protective effects for smoking habits, physical activity, body weight, and having regular health check-ups among people aged 40 to 85 . Our findings confirm that married individuals tend to have healthier lifestyles than non-married individuals (hypothesis 1) with regard to the likelihood of smoking, engaging in physical activity, and having regular health check-ups. Regarding body weight, we found that married people are more likely to be obese than unmarried people who are not in a partnership (contrary to hypothesis 1). This result is challenging, because married people were shown to be more physically active than non-married people. Regarding the conflicting findings, body weight does not necessarily decrease with more physical activity (Fogelholm/Kukkonen-Harjula 2000), especially not with light physical activities, such as housework or gardening among couples (Pettee et al. 2006). An important factor could be the age of the subjects. Studies that also examined older people, reported higher physical activity levels among couples than among people without partnerships (Klein 2009; Pettee et al. 2006). These associations may be explained by the effects of social control of and social support for physical activity 
by partners in old age. For example, Pettee et al. (2006) found that the husband's physical activity participation status was related to the physical activity participation status of his wife. Another possible explanation for the contradictory findings is the tendency of married people to engage in shared leisure time activities that can lead to weight gain, e. g. shared meals at home or in a restaurant (Jeffrey/Rick 2002), and watching television (Voorpostel/Gershuny 2009).

Further, we found only partial support for a protective effect of non-marital partnerships (hypothesis 2). For physical activity and having regular health check-ups, we could confirm our assumption. People in non-marital partnerships were found to have a lower risk of physical inactivity and of avoiding regular health check-ups than unmarried people without a partner.

We also investigated the crisis effect of marriage dissolution on health behaviour (hypothesis 3). According to the assumptions of the crises concept, higher probabilities of smoking, physical inactivity, obesity and avoiding regular health checkups should be found for people who were recently divorced, separated, or widowed than for individuals who were separated, divorced, or widowed a long time ago. The results do not, however, support this assumption.

If we compare the present research results with the findings of other studies, some differences and some new insights can be highlighted. Our results for physical inactivity are contrary to previous findings for younger adults, according to which couples are less likely than singles to engage in sports activities (Rapp/Schneider 2013; Schoeppe et al. 2018). We found, however, that unmarried people-and especially those not in a partnership - have a higher risk of physical inactivity than married people aged 40 and older. These findings are in line with those from studies conducted in the U.S. (King et al. 1998; Pettee et al. 2006), according to which older couples have higher physical activity levels than older unmarried adults. Higher levels of social control and support in older couples may be responsible for the age differences in physical activity levels.

The negative effect of marriage on body weight has mainly been demonstrated for younger people (Klein 2011; Klein et al. 2013) or found in non-European countries (Averett et al. 2008; Sobal et al. 2003). This study provides new insights into the relationship between body weight and marital status for the older population in Germany by showing that the negative relationship between marriage and body weight can be confirmed for people of middle and older adult ages as well.

The findings for health care are similar. The probability of avoiding regular health check-ups was shown to be significantly higher for single, separated, and widowed people than for married couples. On the basis of these results, a protective effect of marriage can be confirmed for the risk of avoiding regular check-ups among people in middle and older adulthood. Theoretically, this relationship is linked to assumptions about the effects of social support and social control. Little is known about the protective effect of marriage on health care behaviour in particular. To extend the evidence in this research area, we investigated the relationship between health care behaviour and marital status.

When comparing our findings on marital status and partnership status, we see that being married has a stronger impact on positive health behaviour than being in 
a non-marital partnership. We can therefore assume that the effects of social support, control, and regulation on health behaviour increase with the institutionalisation of a partnership.

As cross-sectional analysis has limited power, we recommend that future investigations conduct longitudinal evaluations of the effectiveness of protective and crisis effects under the control of selection mechanisms (see Unger 2007). Furthermore, there is a need for research on gender-specific differences in the health behaviours of elderly people, as this type of analysis has so far seldom been done.

The aim of this study was to stimulate further empirical studies that focus on the lifestyles of elderly people in European countries, as more comprehensive evidence is needed in this research field. The results of this study may be helpful in designing behavioural prevention measures and health promotion programmes intended to prevent the development of lifestyle-related risk factors for serious diseases. For example, scientifically-based recommendations could be defined for possible target groups to reduce levels of tobacco consumption and overweight, and to encourage people to have regular health check-ups.

\section{References}

Allison, Paul D. 1999: Comparing Logit and Probit Coefficients Across Groups. In: Sociological Methods \& Research 28,2: 186-208 [doi: 10.1177/0049124199028002003].

Auspurg, Katrin; Hinz, Thomas 2011: Gruppenvergleiche bei Regressionen mit binären abhängigen Variablen - Probleme und Fehleinschätzungen am Beispiel von Bildungschancen im Kohortenverlauf. In: Zeitschrift für Soziologie 40,1: 62-73.

Averett, Susan L.; Sikora, Asia; Argys, Laura M. 2008: For better or worse: relationship status and body mass index. In: Economics and Human Biology 6,3: 330-349 [doi: 10.1016/j.ehb.2008.07.003].

Böhr, Dorothea 2015: Ratschläge in der Partnerschaft - Zum Einfluss des sozialen Netzwerks auf das Gesundheitsverhalten. In: Das Gesundheitswesen 77,08/09 [doi: 10.1055/s-0035-1563261].

Booth, Alan; Amato, Paul 1991: Divorce and Psychological Stress. In: Journal of Health and Social Behavior 32,4: 396-407.

Bröckel, Miriam; Andreß, Hans-Jürgen 2015: The Economic Consequences of Divorce in Germany: What Has Changed since the Turn of the Millennium? In: Comparative Population Studies 40,3: 277-312 [doi: 10.12765/CPoS-2015-04en].

Broms, Ulla et al. 2004: Smoking cessation by socioeconomic status and marital status: the contribution of smoking behavior and family background. In: Nicotine \& tobacco research: Official journal of the Society for Research on Nicotine and Tobacco 6,3: 447-455 [doi: 10.1080/14622200410001696637].

Bulanda, Jennifer Roebuck; Brown, J. Scott; Yamashita, Takashi 2016: Marital quality, marital dissolution, and mortality risk during the later life course. In: Social Science \& Medicine 165: 119-127 [doi: 10.1016/j.socscimed.2016.07.025].

Bulanda, Jennifer R. 2006: Marriage in later life: The relationship between marital quality, health and divorce among older adults. Electronic Thesis or Dissertation. 
Burke, Valerie et al. 1999: Health promotion in couples adapting to a shared lifestyle. In: Health Education Research 14,2: 269-288 [doi: 10.1093/her/14.2.269].

Castro, John M. de 2002: Age-Related Changes in the Social, Psychological, and Temporal Influences on Food Intake in Free-Living, Healthy, Adult Humans. In: The Journals of Gerontology Series A: Biological Sciences and Medical Sciences 57,6: M368-M377 [doi: 10.1093/gerona/57.6.M368].

Chandola, Tarani; Head, Jenny; Bartley, Mel 2004: Socio-demographic predictors of quitting smoking: how important are household factors? In: Addiction 99,6: 770-777 [doi: 10.1111/j.1360-0443.2004.00756.x].

Changik, Jo 2004: Marital Status and Obesity: Cause and Effect. Ph.D. Dissertation. New York.

Chase-Lansdale, Lindsay P.; Hetherington, Mavis E. 2014: The Impact of Divorce on Life-Span Development: Short and Long term Effects. In: Baltes, Paul B.; Featherman, David L.; Lerner, Richard M. (Eds.): Life-Span Devevelopment and Behavior. Life-Span Development and Behavior Series. Hoboken: Taylor and Francis: 107-143.

Cheung, Yin Bun 1998: Can marital selection explain the differences in health between married and divorced people? From a longitudinal study of a British birth cohort. In: Public Health 112;2: 113-117 [doi: 10.1038/sj.ph.1900428].

Cho, Hong-Jun et al. 2008: Marital status and smoking in Korea: the influence of gender and age. In: Social Science \& Medicine 66,3: 609-619 [doi: 10.1016/j.socscimed.2007.10.005].

Choi, Heejeong; Marks, Nadine F. 2008: Marital Conflict, Depressive Symptoms, and Functional Impairment. In: Journal of marriage and the family 70,2: 377-390 [doi: 10.1111/j.1741-3737.2008.00488.x]

Cohen, Sheldon 2004: Social relationships and health. In: The American psychologist 59,8: 676-684 [doi: 10.1037/0003-066X.59.8.676].

Cohen, Sheldon; Wills, Thomas Ashby 1985: Stress, Social Support, and the Buffering Hypothesis. In: Psychological Bulletin 98,2: 310-357.

Committee on Health and Behavior 2001: Health and Behavior: The Interplay of Biological, Behavioral, and Societal Influences. Washington, D.C.: National Academy Press.

Dauphinot, Virginie et al. 2009: New obesity body mass index threshold for self-reported data. In: Journal of Epidemiology and Community Health 63,2: 128-132 [doi: 10.1136/ jech.2008.077800].

Duncan, Greg J.; Wilkerson, Bessie; England, Paula 2006: Cleaning Up Their Act. The Effects of Marriage and Cohabitation on Licit and Illicit Drug Use. In: Demography 43,4: 691-710 [doi: 10.1353/dem.2006.0032].

Engstler, Heribert; Hameister, Nicole 2016: Deutscher Alterssurvey (DEAS): Kurzbeschreibung des Datensatzes SUF DEAS2014, Version 1.0. Berlin: Deutsches Zentrum für Altersfragen.

Floyd, Kory et al. 2006: Positive behaviors during marital conflict. Influences on stress hormones. In: Journal of Social and Personal Relationships 23,2: 305-325 [doi: 10.1177/0265407506062482].

Fogelholm, Mikael; Kukkonen-Harjula, Katriina 2000: Does physical activity prevent weight gain - a systematic review. In: Obesity Reviews 1,2: 95-111 [doi: 10.1046/j.1467789x.2000.00016.x].

Fuller, Theodore D. 2010: Relationship Status, Health, and Health Behavior: An Examination of Cohabiters and Commuters. In: Sociological Perspectives 53,2: 221-246 [doi: 10.1525/sop.2010.53.2.221]. 
Goldman, Noreen 1993: Marriage Selection and Mortality Patterns: Inferences and Fallacies. In: Demography 30,2: 189-208.

Goldman, Noreen; Korenman, Sanders; Weinstein, Rache/ 1995: Marital status and health among the elderly. In: Social Science \& Medicine 40,12: 1717-1730 [doi: 10.1016/02779536(94)00281-W].

Graham, John W.; Cumsille, Patricio E.; Elek-Fisk, Elvira 2003: Methods for Handling Missing Data. In: Schinka, John A.; Velicer, Wayne F. (Eds.): Handbook of psychology: Research methods in psychology 2. New York: John Wiley \& Sons: 87-114 [doi: 10.1002/0471264385.wei0204].

Greeno, Catherine G.; Wing, Rena R. 1994: Stress-induced eating. In: Psychological Bulletin 115,3: 444-464 [doi: 10.1037/0033-2909.115.3.444].

Gross, Christiane; Groß, Jochen 2008: Rational-Choice-Erklärungen zum Rauchverhalten und ihre empirische Relevanz. In: Soziale Welt 59: 247-268.

Grundy, Emily; Tomassini, Cecilia 2010: Marital history, health and mortality among older men and women in England and Wales. In: BMC Public Health 10: 554 [doi: 10.1186/1471-2458-10-554].

Grundy, Emily; Sloggett, Andy 2003: Health inequalities in the older population. The role of personal capital, social resources and socio-economic circumstances. In: Social Science \& Medicine 56,5: 935-947.

Hanske, Julian et al. 2016: The influence of marital status on the use of breast, cervical, and colorectal cancer screening. In: Preventive medicine 89: 140-145 [doi: 10.1016/j. ypmed.2016.05.017].

Haveman-Nies, Annemien; Groot, Lisette de; van Staveren, Wija A. 2003: Dietary quality, lifestyle factors and healthy ageing in Europe. The SENECA study. In: Age and Ageing 32,4: 427-434 [doi: 10.1093/ageing/32.4.427].

Heaney, Catherine; Israel, Barbara A. 2008: Social Networks and Social Support. In: Glanz, Karen; Rimer, Barbara K.; Viswanath, K. (Eds.): Health behavior and health education. Theory, research, and practice. San Francisco, CA: Jossey-Bass: 189-210.

Helmert, Uwe; Borgers, Dieter; Bammann, Karin 2001: Soziale Determinanten des Rauchverhaltens in Deutschland: Ergebnisse des Mikrozensus 1995. In: International Journal of Public Health 46,3: 172-181 [doi: 10.1007/BF01324253].

Homish, Gregory G.; Leonard, Kenneth E. 2005: Spousal influence on smoking behaviors in a US community sample of newly married couples. In: Social Science \& Medicine 61,12: 2557-2567 [doi: 10.1016/j.socscimed.2005.05.005].

House, James S.; Landis, Karl R.; Umberson, Debra 1988: Social Relationship and Health. In: Science, New Series 4865: 540-545.

Hu, Yuanreng; Goldman, Noreen 1990: Mortality Differentials by Marital Status: An International Comparison. In: Demography 27,2: 233-250.

Hughes, Mary Elizabeth; Waite, Linda J. 2009: Marital Biography and Health at Mid-Life. In: Journal of Health and Social Behavior 50,3: 344-358 [doi: 10.1177/ 002214650905000307].

infas 2009: Alterssurvey 2008. Die zweite Lebenshälfte. Durchführung der 3. Befragungswelle. Methodenbericht. Bonn.

Jeffery, Robert W.; Rick, Allison M. 2002: Cross-sectional and longitudinal associations between body mass index and marriage-related factors. In: Obesity Research 10,8: 809-815 [doi: 10.1038/oby.2002.109]. 
Joung, Inez M.A.; van de Mheen, H. Dike; Stronks, Karien; van Poppel, Frans W.A.; Mackenbach, Johan P. 1998: A longitudinal study of health selection in marital transitions. In: Social Science \& Medicine 46;3: 425-435. [doi: 10.1016/S0277-9536(97)00186-X].

Joung, Inez M.A et al. 1994: Differences in Self-Reported Morbidity by Marital Status and by Living Arrangement. In: International Journal of Epidemiology 23,1: 91-97 [doi: 10.1093/ije/23.1.91].

Kaplan, Mark S. et al. 2001: Demographic and psychosocial correlates of physical activity in late life. In: American Journal of Preventive Medicine 21,4: 306-312 [doi: 10.1016/ S0749-3797(01)00364-6].

King, Abby C. et al. 1998: The effects of marital transitions on changes in physical activity: results from a 10-year community study. In: Annals of behavioral medicine: a publication of the Society of Behavioral Medicine 20,2: 64-69 [doi: 10.1007/BF02884450].

Klaus, Daniela; Engstler, Heribert 2016: Daten und Methoden des Deutschen Alterssurveys. In: Mahne, Katharina et al. (Eds.): Altern im Wandel: Zwei Jahrzehnte Deutscher Alterssurvey (DEAS). Berlin: Deutsches Zentrum für Altersfragen (DZA): 25-42.

Klein, Thomas 1993: Soziale Determinanten der Lebenserwartung. In: Kölner Zeitschrift für Soziologie und Sozialpsychologie 45,4: 712-730.

Klein, Thomas 2009: Determinanten der Sportaktivität und der Sportart im Lebenslauf. In: KZfSS Kölner Zeitschrift für Soziologie und Sozialpsychologie 61,1: 1-32. [doi: 10.1007/s11577-009-0040-2].

Klein, Thomas 2011: „Durch Dick und Dünn.“ Zum Einfluss von Partnerschaft und Partnermarkt auf das Körpergewicht. In: Kölner Zeitschrift für Soziologie und Sozialpsychologie 63,3: 459-479 [doi: 10.1007/s11577-011-0143-4].

Klein, Thomas; Rapp, Ingmar; Schneider, Björn 2013: Der Einfluss der partnerschaftlichen Lebensform auf Rauchverhalten und Körpergewicht. In: Zeitschrift für Bevölkerungswissenschaft 38,3: 649-672. [doi: 10.4232/10.CPoS-2013-13de].

Lipowicz, Anna 2014: Some evidence for health-related marriage selection. In: American journal of human biology: the official journal of the Human Biology Council 26,6: 747-752 [doi: 10.1002/ajhb.22588].

Manzoli, Lamberto et al. 2007: Marital status and mortality in the elderly: a systematic review and meta-analysis. In: Social Science \& Medicine 64,1: 77-94 [doi: 10.1016/j. socscimed.2006.08.031].

Margolis, Rachel; Wright, Laura 2016: Better Off Alone Than With a Smoker: The Influence of Partner's Smoking Behavior in Later Life. In: The journals of gerontology. Series $B$, Psychological sciences and social sciences 71,4: 687-697 [doi: 10.1093/geronb/ gbu220].

Mathers, Colin 2012: WHO global report. Mortality attributable to tobacco. Geneva, Switzerland: World Health Organization.

Mood, Carina 2010: Logistic Regression: Why We Cannot Do What We Think We Can Do, and What We Can Do About It. In: European Sociological Review 26,1: 67-82 [doi: 10.1093/esr/jcp006].

Moon, J. Robin et al. 2011: Widowhood and mortality: a meta-analysis. In: PloS one 6,8: e23465 [doi: 10.1371/journal.pone.0023465].

Nowossadeck, Sonja; Engstler, Heribert 2013: Familie und Partnerschaft im Alter. Report Altersdaten 3/2013. Deutsches Zentrum für Altersfragen: Berlin.

Nystedt, Paul 2006: Marital life course events and smoking behaviour in Sweden 1980-2000. In: Social Science \& Medicine 62,6: 1427-1442 [doi: 10.1016/j.socscimed.2005.08.009]. 
OECD 1999: Classifying educational programmes. Manual for ISCED-97 implementation in OECD countries. 1999 ed. Paris: Organisation for Economic Co-operation and Development.

Pampel, Fred C.; Krueger, Patrick M.; Denney, Justin T. 2010: Socioeconomic Disparities in Health Behaviors. In: Annual Rreview of Ssociology 36: 349-370 [doi: 10.1146/ annurev.soc.012809.102529].

Peltonen, Riina et al. 2017: Contribution of smoking-attributable mortality to life expectancy differences by marital status among Finnish men and women, 1971-2010. In: Demographic Research 36,8: 255-280 [doi: 10.4054/DemRes.2017.36.8].

Pettee, Kelley K. et al. 2006: Influence of marital status on physical activity levels among older adults. In: Medicine and science in sports and exercise 38,3: 541-546 [doi: 10.1249/01.mss.0000191346.95244.f7].

Perkins, Jessica M. et al. 2016: Marital status, widowhood duration, gender and health outcomes: a cross-sectional study among older adults in India. In: BMC public health 16,1: 1032 [doi: 10.1186/s12889-016-3682-9].

Prigerson, Holly G.; Maciejewski, Paul K.; Rosenheck, Robert A. 1999: The effects of marital dissolution and marital quality on health and health service use among women. In: Medical care 37,9: 858-873 [doi: 10.1097/00005650-199909000-00003].

Psouni, Stavroula; Hassandra, Mary; Theodorakis, Yannis 2016: Patterns of Eating and Physical Activity Attitudes and Behaviors in Relation to Body Mass Index. In: Psychology 7,2: 180-192 [doi: 10.4236/psych.2016.72020].

Rapp, Ingmar 2012: In Gesundheit und Krankheit? In: Kölner Zeitschrift für Soziologie und Sozialpsychologie 64,4: 783-803 [doi: 10.1007/s11577-012-0184-3].

Rapp, Ingmar; Klein, Thomas 2015: Familie und Gesundheit. In: Hill, Paul B.; Kopp, Johannes (Eds.): Handbuch Familiensoziologie. Wiesbaden: Springer Fachmedien Wiesbaden: 775-790.

Rapp, Ingmar; Schneider, Björn 2013: The impacts of marriage, cohabitation and dating relationships on weekly self-reported physical activity in Germany: a 19-year longitudinal study. In: Social Science \& Medicine 98: 197-203 [doi: 10.1016/j.socscimed.2013.09.024].

Reczek, Corinne et al. 2016: Marital Histories and Heavy Alcohol Use among Older Adults. In: Journal of health and social behavior 57,1: 77-96 [doi: 10.1177/0022146515 628028].

Robards, James et al. 2012: Marital status, health and mortality. In: Maturitas 73,4: 295299 [doi: 10.1016/j.maturitas.2012.08.007].

Roelfs, David J. et al. 2011: The rising relative risk of mortality for singles: Meta-analysis and meta-regression. In: American Journal of Epidemiology 174,4: 379-389. [doi: 10.1093/aje/kwr111].

Sbarra, David A.; Nietert, Paul J. 2009: Divorce and death: forty years of the Charleston Heart Study. In: Psychological science 20,1: 107-113 [doi: 10.1111/j.1467-9280. 2008.02252.x.].

Schmidtke, Kerstin; Meyer, Sophie 2011: Soziale Einflussfaktoren auf das Gesundheitsverhalten und den Gesundheitszustand. Ergebnisse des Mikrozensus. Band 69. Düsseldorf: Information und Technik Nordrhein-Westfalen.

Schoeppe, Stephanie et al. 2018: Do singles or couples live healthier lifestyles? Trends in Queensland between 2005-2014. In: PloS one 13,2: e0192584 [doi: 10.1371/journal. pone.0192584]. 
Schulze, Alexander; Lampert, Thomas 2006: Bundes-Gesundheitssurvey: Soziale Unterschiede im Rauchverhalten und in der Passivrauchbelastung in Deutschland. Beiträge zur Gesundheitsberichterstattung des Bundes. Berlin: Robert Koch-Institut.

Sobal, Jeffery; Rauschenbach, Barbara; Frongillo, Edward A. 2003: Marital status changes and body weight changes: a US longitudinal analysis. In: Social Science \& Medicine 56,7: 1543-1555 [doi: 10.1016/S0277-9536(02)00155-7].

Soulsby, Laura K.; Bennett, Kate M. 2015: Marriage and Psychological Wellbeing. The Role of Social Support. In: Psychology 06,11: 1349-1359 [doi: 10.4236/psych.2015.611132].

Spegel, Hedwig et al. 1999: Muster des Gesundheitsverhaltens und ihre Determinanten? Ergebnisse des Bern-Münchner Lebensstilpanels. In: Sozial- und Präventivmedizin SPM 44,4: 160-170 [doi: 10.1007/BF01300272].

Tamers, Sara L. et al. 2014: The impact of stressful life events on excessive alcohol consumption in the French population: findings from the GAZEL cohort study. In: PloS one 9,1: e87653 [doi: 10.1371/journal.pone.0087653].

Uchino, Bert N. 2004: Social support and physical health. Understanding the health consequences of relationships. Current perspectives in psychology. New Haven: Yale University Press.

Umberson, Debra 1992: Gender, marital status and the social control of health behavior. In: Social Science \& Medicine 34,8: 907-917 [doi: 10.1016/0277-9536(92)90259-S].

Umberson, Debra; Crosnoe, Robert; Reczek, Corinne 2010: Social Relationships and Health Behavior Across Life Course. In: Annual review of sociology 36: 139-157 [doi: 10.1146/annurev-soc-070308-120011].

Umberson, Debra; Liu, Hui; Powers, Daniel 2009: Marital Status, Marital Transitions, and Body Weight. In: Journal of Health and Social Behavior 50,3: 327-343 [doi: 10.1177/002214650905000306].

Unger, Rainer 2007: Gesundheit im Lebenslauf. Zur relativen Bedeutung von Selektionsgegenüber Kausaleffekten am Beispiel des Familienstands. In: SOEPpapers on Multidisciplinary Panel Data Research 54.

van Loon, A. Jeanne M. et al. 2005: Determinants of smoking status: cross-sectional data on smoking initiation and cessation. In: European Journal of Public Health 15,3: 256-261 [doi: 10.1093/eurpub/cki077].

Verbrugge, Lois M. 1979: Marital Status and Health. In: Journal of Marriage and the Family 41,2: 267-285.

Voorpostel, Marieke; van der Lippe, Tanja; Gershuny, Jonathan 2009: Trends in Free Time with a Partner: A Transformation of Intimacy? In: Social indicators research 93,1: 165-169 [doi: 10.1007/s11205-008-9383-8].

Waite, Linda J.; Gallagher, Maggie 2000: The case for marriage. Why married people are happier, healthier, and better off financially. New York: Doubleday.

Waldron, Ingrid; Hughes, Mary Elizabeth; Brooks, Tracy L. 1996: Marriage protection and marriage selection - Prospective evidence for reciprocal effects of marital status and health. In: Social Science \& Medicine 43,1: 113-123 [doi: 10.1016/0277-9536(95)003479].

Wilcox, Sara et al. 2003: The effects of widowhood on physical and mental health, health behaviors, and health outcomes: The Women's Health Initiative. In: Health psychology: official journal of the Division of Health Psychology, American Psychological Association 22,5: 513-522 [doi: 10.1037/0278-6133.22.5.513]. 
Williams, Kristi; Umberson, Debra 2004: Marital Status, Marital Transitions, and Health: A Gendered Life Course Perspective. In: Journal of Health and Social Behavior 45,1: 81-98 [doi: 10.1177/002214650404500106].

Wilkinson, Richard; Marmot, Michael 2003: Social Determinants of Health: The solid facts. Copenhagen: World Health Organization, Regional Office for Europe.

World Health Organization 2000: Obesity: Preventing and managing the global epidemic. Report of a WHO Consulation. WHO Technical Report Series 894. Geneva.

World Health Organization 2009: Global Health Risks. Mortality and burden of disease attributable to selected major risks. Geneva: WHO Press.

Wyke, Sally; Ford, Graeme 1992: Competing explanations for associations between marital status and health. In: Social Science \& Medicine 34,5: 523-532 [doi: 10.1016/02779536(92)90208-8].

Yim, Hyun Ji et al. 2012: Marital Status and Health Behavior in Middle-aged Korean Adults. In: Korean Journal of Family Medicine 33,6: 390-397 [doi: 10.4082/kjfm.2012.33.6.390].

Yom Din, Gregory; Zugman, Zinaida; Khashper, Alla 2014: The Impact of Preventive Health Behaviour and Social Factors on Visits to the Doctor. In: Israel Journal of Health Policy Research 3: 41 [doi: 10.1186/2045-4015-3-41].

Regina Hilz $(\bowtie)$. University of Cologne, Doctoral Programme GROW-Gerontological Research on Well-Being. Cologne, Germany. E-mail: rhilz@uni-koeln.de, URL: http://www.hf.uni-koeln.de/37539

Prof. Dr. Michael Wagner. University of Cologne, Institute of Sociology and Social Psychology (ISS). Cologne, Germany. E-mail: mwagner@wiso.uni-koeln.de,

URL: http://www.iss-wiso.uni-koeln.de/en/institute/staff/w/prof-dr-michael-wagner/ 


\section{Appendix}

Tab. A1: Number of intrapersonal changes in health behaviour after marriage dissolution

\begin{tabular}{|c|c|c|}
\hline DEAS 2008, 2011, 2014 & after separation/divorce & after widowhood \\
\hline \multicolumn{3}{|l|}{ Smoking status } \\
\hline change from smoker to non-smoker & $3(11 \%)$ & $1 \quad(2 \%)$ \\
\hline change from non-smoker to smoker & $3(11 \%)$ & $1 \quad(2 \%)$ \\
\hline no change & $21(78 \%)$ & $58(96 \%)$ \\
\hline $\mathrm{N}$ & $27(100 \%)$ & $60(100 \%)$ \\
\hline \multicolumn{3}{|l|}{ Physical activity } \\
\hline reduction of physical activity & $5(11 \%)$ & $7 \quad(7 \%)$ \\
\hline increase in physical activity & $15(34 \%)$ & $29(31 \%)$ \\
\hline no change & $24(55 \%)$ & $58(62 \%)$ \\
\hline $\mathrm{N}$ & $44(100 \%)$ & $94(100 \%)$ \\
\hline \multicolumn{3}{|l|}{ Check-up } \\
\hline participation before the event & $2(7 \%)$ & $2 \quad(5 \%)$ \\
\hline participation after the event & $2 \quad(7 \%)$ & $10(16 \%)$ \\
\hline no change & $23(86 \%)$ & $48(79 \%)$ \\
\hline $\mathrm{N}$ & $27(100 \%)$ & $60(100 \%)$ \\
\hline \multicolumn{3}{|l|}{ BMI } \\
\hline lost weight & $43(98 \%)$ & $94(100 \%)$ \\
\hline gained weight & $0 \quad(0 \%)$ & 0 \\
\hline no weight change & $1 \quad(2 \%)$ & 0 \\
\hline $\mathrm{N}$ & $44(100 \%)$ & $94(100 \%)$ \\
\hline
\end{tabular}

Source: Own calculations based on the samples of 2008, 2011 and 2014 of the German Ageing Survey (DEAS), unweighted. 


\section{Comparative Population Studies}

WWW.comparativepopulationstudies.de

ISSN: 1869-8980 (Print) - 1869-8999 (Internet)

\section{Published by}

Prof. Dr. Norbert F. Schneider

Federal Institute for Population Research D-65180 Wiesbaden / Germany

\section{(cc) BY-SA}

2018

\section{Managing Editor}

Dr. Katrin Schiefer

\section{Copy Editor}

Dr. Evelyn Grünheid

Dr. Katrin Schiefer

\section{Editorial Assistant}

Beatriz Feiler-Fuchs

Wiebke Hamann

\section{Layout \\ Beatriz Feiler-Fuchs \\ E-mail:cpos@bib.bund.de}

\section{Scientific Advisory Board}

Karsten Hank (Cologne)

Michaela Kreyenfeld (Berlin)

Marc Luy (Vienna)

Peter Preisendörfer (Mainz)

Nikola Sander (Wiesbaden)

Zsolt Spéder (Budapest)

Rainer Wehrhahn (Kiel)

\section{Board of Reviewers}

Martin Abraham (Erlangen)

Laura Bernardi (Lausanne)

Hansjörg Bucher (Bonn)

Claudia Diehl (Konstanz)

Andreas Diekmann (Zurich)

Gabriele Doblhammer-Reiter (Rostock)

Jürgen Dorbritz (Wiesbaden)

Anette Eva Fasang (Berlin)

E.-Jürgen Flöthmann (Bielefeld)

Alexia Fürnkranz-Prskawetz (Vienna)

Beat Fux (Salzburg)

Joshua Goldstein (Berkeley)

Sonja Haug (Regensburg)

Hill Kulu (Liverpool)

Aart C. Liefbroer (The Hague)

Kurt Lüscher (Konstanz)

Emma Lundholm (Umeå)

Nadja Milewski (Rostock)

Dimiter Philipov (Vienna)

Roland Rau (Rostock)

Tomáš Sobotka (Vienna)

Jeroen Spijker (Barcelona)

Olivier Thévenon (Paris)

Helga de Valk (Brussels)

Heike Trappe (Rostock)

Michael Wagner (Cologne) 